\title{
\#TodossomosAyotzinapa. Storytelling, identidades, representaciones y reflexividad en disputa
}

\author{
\#TodossomosAyotzinapa. Storytelling, Identities, \\ Representations and Reflexivity in Dispute
}

\author{
DRA. MARÍA ELENA MENESES ROCHA \\ MTRA. MARÍA CONCEPCIÓN CASTILLO GONZÁLEZ \\ INSTITUTO TECNOLÓGICO DE MONTERREY
}

Artículo recibido el / Article received: 14-10-2015

Artículo aceptado el / Article accepted: 17-10-2016

RESUMEN: El objetivo del artículo es explicar la disputa y relaciones de poder articuladas a través del storytelling como herramienta y práctica social con una aproximación desde los Estudios culturales. Se contrastó el storytelling de grupos de la sociedad civil con el del gobierno en la plataforma YouTube sobre el caso de desapariciones forzadas en Ayotzinapa México entre septiembre y diciembre de 2014. El análisis comparativo permitió palpar la lucha por la representación, las contradicciones del gobierno mexicano y los desencuentros entre ambos actores sobre un caso histórico de violación a los derechos fundamentales. Se discuten las posibilidades y limitantes del storytelling para organizar la protesta, para el cambio social, así como para la transformación positiva y pacífica de los conflictos. Asimismo se reflexiona sobre la utilidad de las herramientas de curación de contenidos en redes sociales para la investigación en ciencias sociales.

Palabras clave: storytelling, cambio social, redes sociales, acción colectiva, Ayotzinapa, YouTube, representaciones, reflexividad.

ABSTRACT: The aim of this article is to explain the dispute and power relations articulated through the storytelling as a tool and social practice. Through a Cultural Studies approach we compared the civil society storytelling with the one of federal government in YouTube on the case of forced disappearances in Ayotzinapa, Mexico between September and December 2014. At the same time we observed the socio-political context, mass media coverage and it's global reach. The comparative analysis allows to understand the representations, contradictions and disagreements between the actors around this case of Human Rights violation 
and the possibilities and limitations of storytelling to organize protest, to obtain social incidence and the peaceful transformation of conflict. The paper discusses the value of digital tools for Social Sciences research.

Keywords: storytelling, social change, social networks, collective action, ayotzinapa, Youtube, representations, reflexivity.

\section{INTRODUCCIÓN}

\section{1. \#TodossomosAyotzinapa}

El objetivo del artículo es identificar la narrativa de la sociedad civil en la plataforma YouTube y contrastarlo con la del gobierno federal sobre el caso de la desaparición de 43 estudiantes de la Escuela Normal de Ayotzinapa en el estado de Guerrero, para tener una mejor comprensión de las dinámicas comunicativas de representación, de la acción colectiva y la posible incidencia de cambio social de un caso que tuvo alcance global por su gravedad. ${ }^{1}$ Exploramos el storytelling de ambos actores con el fin de entender a los medios como práctica social, es decir, no solo cómo se representa al mundo social, sino cómo ocurre este en los medios (Couldry, 2012). El hecho causó una de las más grandes crisis políticas del gobierno del presidente Enrique Peña Nieto, quien reaccionó de manera tardía ante la desaparición forzada de los estudiantes. La visibilidad a nivel global del acontecimiento expuso contradicciones inherentes con el discurso oficial y la imagen de los medios tradicionales de un gobierno renovador y salvador de México, como lo proclamó la revista Time el 24 de febrero de 2014 (Crowley, 2014). ${ }^{2}$

Observamos el flujo de mensajes durante los tres meses posteriores al 27 de septiembre de 2014, fecha en la que medios nacionales informaron sobre el asesinato de seis personas y la desaparición de 43 estudiantes normalistas en la localidad de Ayotzinapa, al sur de México. El ecosistema digital contribuyó a

1. El estado mexicano de Guerrero tiene uno de los mayores índices de violencia en el país. En 2014 registró una tasa de 65 homicidios por cada 100.000 habitantes, según un informe del INEGI.

2. La Asamblea General de Naciones Unidas (1993) considera que las desapariciones forzadas afectan los valores profundos de toda sociedad respetuosa de la primacía del Derecho, de los derechos humanos y de las libertades fundamentales, y que su práctica sistemática representa un crimen de lesa humanidad. 
dimensionar y amplificar el caso ante la falta de respuestas del gobierno federal a un caso que, si bien tuvo lugar en un municipio, ameritaba por su gravedad la atención de la federación. Nos preguntamos cómo este hecho fue representado por los grupos de la sociedad civil y por el gobierno federal respectivamente, para comprender las dinámicas y relaciones de poder articuladas mediante el storytelling como herramienta y práctica social. Observamos dos cuestiones: los códigos usados como valores de representación por ambos sujetos de estudio para detectar coincidencias y confrontaciones en disputa en la esfera pública, compuesta por medios digitales y convencionales, y paralelamente, no perdimos de vista el contexto en el cual la indignación pasó de las plataformas digitales a la acción colectiva con protestas que llevaron al gobierno federal a atender el caso.

En México es relevante hacerse estas preguntas ya que se observan expectativas sociales con respecto al poder de las redes sociales en un contexto de escasa confianza institucional, estrecha pluralidad mediática (Trejo, 2011; Noam, 2011) e incipiente cultura participativa, de la cual dan cuenta estudios nacionales e internacionales (INE, 2014; WEF, 2014). ${ }^{3}$

Los discursos y las imágenes del otoño mexicano no pertenecen únicamente a los gobernantes y políticos, los anclajes simbólicos de la indignación fueron resignificados por las redes sociales digitales. El hashtag \#TodossomosAyotzinapa en un solo día consiguió 111.000 menciones en Twitter, en contraste con el tardío discurso oficial que tuvo lugar once días después. La indignación pasó al mundo offline, en tres meses se realizaron 55 manifestaciones: la mayoría en la capital del país (41\%) y 13 en el estado de Guerrero. Un 98\% de los mexicanos, según la encuesta de la consultora Parametría (2014), tuvo conocimiento de las marchas ciudadanas que, por número de manifestaciones, representaron hasta 2014 el 44\% de la movilización ciudadana en el gobierno de Enrique Peña Nieto.

Los internautas tomaron las plataformas digitales para difundir información, protestar y organizar movilizaciones que traspasaron lo virtual y que pudieron influir en la crisis de popularidad del presidente, observada en los meses posteriores a los hechos, si bien se deben añadir otras causas relacionadas con acusaciones contra él y su esposa por conflicto de interés en la compra de una

3. En 2014, un estudio elaborado por el Instituto Nacional Electoral (INE, 2014) encontró que los mexicanos perciben escasos canales de participación sobre asuntos políticos en el país. De acuerdo con este estudio, apenas un 39\% de los electores indicó hablar con alguien de asuntos políticos. Otros informes, como el del Foro Económico Mundial (WEF, 2014), dan a México puntajes muy bajos en cuanto a confianza institucional. 
casa de 7 millones de dólares (Redacción AN, 2014). La desaprobación ciudadana al presidente entre agosto y diciembre de 2014, según una encuesta del diario Reforma, subió del $46 \%$ al $58 \%$, porcentaje que no registraba un gobernante mexicano desde hacía 19 años (Animal Político, 2014).

\section{ESTADO DE LA CUESTIÓN}

\subsection{Plataformas digitales $y$ forma cultural}

Reconocemos que en la apropiación social de la tecnología no hay una lógica unívoca y unidimensional, y, como Williams (2011) lo propuso desde la década de 1970 en sus estudios sobre la televisión, los investigadores debemos enfocar el análisis en los significados, interacciones y tensiones, es decir, en su forma cultural. Esta puede indagarse en el lenguaje, las narrativas y los marcos de interpretación (Goffman,1974) que se encuentran ligados al contexto en el cual se desenvuelven los agentes sociales y sus proyectos reflexivos, entendidos como autoconfrontación y capacidad de transformar la sociedad por parte de ciertos actores sociales (Beck, 2007).

Las plataformas digitales permiten formas personalizadas y flexibles de involucramiento y agenciamiento (Bennett \& Segerberg, 2012). Su narrativa audiovisual, formatos, encuadres, difusión viral y la participación de los usuarios, sugieren la articulación de inéditas formas y significados que eventualmente pudieran articular un complejo sistema en red de concienciación (Papacharissi \& Oliveria, 2012) y transformación de las relaciones de poder (Castells, 2012). Por plataformas digitales entendemos 'los espacios de interacción predeterminados como redes sociales, buscadores y aplicaciones que están mediados por dispositivos fijos o móviles' (Van Dijck, 2013). Si bien observamos dichas plataformas como un ecosistema dinámico de conexiones sociales interrelacionadas, en este trabajo se indagará únicamente YouTube, como sistema cultural que favorece la cultura participativa ciudadana y como expresión de la convergencia de diferentes modos de producción cultural (Burguess \& Green, 2009). ${ }^{4}$

4. Este dinamismo de la ecología de plataformas diversas es patente desde la perspectiva económica. Por ejemplo, YouTube fue adquirida por Google en 2006; Facebook a su vez adquirió Instagram en 2012; y WhatsApp, en 2014. 


\section{2. «Storytelling» como práctica social}

El «storytelling» ha sido estudiado como algo más que contar historias (Lambert, 2006), como el empoderamiento de los grupos excluidos de la «polis» (Jackson, 2002) y como herramienta social (Tilly, 2002). Para comprender este fenómeno como práctica social no basta con aislar el discurso de la experiencia cotidiana, por ello observamos la agenda de los medios tradicionales y lo que sucedía en las calles de México en 2014 para contrastar el «storytelling» de la sociedad civil con el oficial.

$\mathrm{El}$ «storytelling» produce conexiones afectivas y emocionales que contribuyen a la construcción ciudadana contemporánea, utilizando temas, valores y códigos universales (Burgess, 2006; Poletti, 2011; Papacharissi \& Oliveria, 2012). Se trata de discursos creativos con potencial para activar el reconocimiento social de los invisibilizados en el sistema (Honneth, 2007). Otros identifican al arte de narrar historias desde una perspectiva de comunicación estratégica para el desarrollo como eduentretenimiento (Tufte, 2015); pues «la forma en que las ideas y realidades sociales se representan influye en el modo en que las personas piensan de ellas, se relacionan con ellas y actúan en consecuencia» (Nos, Iranzo y Farné, 2012: 214). En esas formas culturales producidas y narradas pueden descubrirse también claves de la acción humana donde convergen individuos, organizaciones, redes y lugares (Tilly, 2002) y desentrañarse los aspectos simbólicos de una acción colectiva por lo que Melucci (1996) entiende las formas de confrontación con el Estado detonadas por el descontento y marginación que genera un sistema social, de naturaleza diversa y compleja con poderosos significados culturales.

La creatividad y el agenciamiento ciudadano, mediante el discurso audiovisual en las plataformas digitales, orientados a la concienciación y a la acción colectiva, son propios de quienes tienen habilidades digitales y lo que Bengtsson y Christensen (2012) llaman competencia política. Aludir la participación política es pertinente en países como México, donde la cultura cívica es incipiente y prevalece la brecha digital con 70 millones de personas desconectadas (INEGI, 2013; INE,2014). Aun así, entre los conectados se desarrollan las redes de indignación (Castells, 2012), tal como ocurrió en la historia reciente de México con el movimiento estudiantil \#Yosoy132 (Meneses, 2015) y que además configuran una opinión pública supranacional (Sampedro y Resina, 2010).

Se puede constatar que es en el ecosistema digital, conformado por plataformas múltiples como la analizada en este trabajo, en donde anida la identidad de resistencia con respecto al poder tradicional (Hall \& Jefferson, 2014; Castells, 2004), así como la política de confrontación (Tilly, 2002). El «storyte- 
lling» como práctica emergente mediatizada (Couldry, 2008) e impregnada de afectividad (Papacharissi, 2015) marca una importante diferencia política y cultural con las formas de contar la historia mainstream, si bien reconocemos que códigos provenientes de la cultura de medios tradicional junto con los códigos digitales - como el software, los dispositivos, la instantaneidad, la viralidad y la participación de los usuarios, entre otros atributos sociotécnicos- fluyen, entremezclan fragmentos y resignifican la práctica comunicativa y la política.

\section{MÉTODO}

Resulta desafiante elegir un corpus para el análisis en las plataformas digitales como YouTube. Se sorteó esta dificultad orientando la indagación bajo el criterio de viralidad y buscando manualmente el tipo de productores audiovisuales de la sociedad civil organizada. Para buscar de manera más ágil y objetiva el corpus usamos herramientas digitales como la desarrollada por la Cátedra Datos de la Universidad de Buenos Aires, ${ }^{5}$ combinada con búsqueda manual. Encontramos 420 videos, quitamos los que tenían menos de 20.000 vistas y, mediante un trabajo de análisis de los perfiles uno por uno, desechamos a los productores no pertenecientes a la sociedad civil, así como a los que no permitían el análisis de los relatos como conferencias, podcasts, etc., quedándonos con 203. A este corpus aplicamos la fórmula desarrollada por Castillo y Meneses (2015) basada en los datos de la propia plataforma para medir la viralidad de los mensajes de la sociedad civil producidos para confrontar al gobierno federal y que se basa en los estudios de Jenkins (2013) sobre dispersión y viralidad. Así, conseguimos obtener un corpus manejable que respondiera al objetivo de analizar únicamente la narrativa producida por grupos de la sociedad civil organizada con un nivel importante de viralidad.

5. La Cátedra Datos es parte de la Carrera de Comunicación de la Facultad de Ciencias Sociales de la Universidad de Buenos Aires. Como parte de sus indagaciones en humanidades digitales, generó el prototipo de una aplicación abierta para la búsqueda de videos masivos en YouTube. La herramienta funcionaba como un intermediario que facilitaba el acceso y almacenamiento de datos en tablas de Excel con la mayoría de las estadísticas públicas que ofrece la plataforma. El prototipo, actualmente fuera de funcionamiento, fue desarrollado por @Palamago con base en las ideas de@ginocingolani, @ailensalamone y @martinked. Liga al prototipo: http://goo. $\mathrm{gl} / \mathrm{a} 2 \mathrm{rfCx}$. 


\section{\#veces compartido/ vistas reportadas*100}

\section{Figura 1. Nivel de propagación (viralidad)}

Mediante nuestra observación de los perfiles identificamos nueve diferentes tipos de productores de la sociedad civil organizada: estudiantes, youtubers, internautas independientes, agencias libres de comunicación digital, músicos, colectivos de información alternativa, organismos no gubernamentales, periodistas independientes y blogs de activismo, quienes desde sus cuentas hicieron públicas sus creaciones y pertenencia. De esta forma, luego de aplicar la fórmula y observar estos criterios de manera manual seleccionamos los nueve videos más virales por cada tipo de productor publicados entre el 27 de septiembre y el 31 de diciembre de 2014, quedando la muestra de la siguiente forma:

Tabla 1. \#Ayotzinapa en YouTube

\begin{tabular}{|c|c|c|c|}
\hline Productor & Título & $\begin{array}{c}\text { Tipo } \\
\text { de producción }\end{array}$ & Propuesta \\
\hline $\begin{array}{l}\text { Youtuber: Parok, } \\
\text { Shd. }\end{array}$ & $\begin{array}{l}\text { Solo quería ser } \\
\text { maestro Ayotzinapa } \\
\text { canción + link de } \\
\text { descarga. }\end{array}$ & Casera, musical. & $\begin{array}{l}\text { Revolución/ } \\
\text { derrocarmiento. }\end{array}$ \\
\hline $\begin{array}{l}\text { Internauta desde } \\
\text { su cuenta: López, } \\
\text { A. V. }\end{array}$ & $\begin{array}{l}\text { Versos de Ayotzi- } \\
\text { napa- Carmina Can- } \\
\text { navino. }\end{array}$ & Casera, musical. & $\begin{array}{l}\text { Reflexiva: cambio } \\
\text { social-institucional. }\end{array}$ \\
\hline $\begin{array}{l}\text { Periodista } \\
\text { independiente: } \\
\text { Reynoso, G. }\end{array}$ & $\begin{array}{l}\text { Performance Ayo- } \\
\text { tzinapa. Estudiantes } \\
\text { y maestros de la } \\
\text { ENAT 16/10/14 (GRL } \\
9182) .\end{array}$ & $\begin{array}{l}\text { Instantánea. } \\
\text { Expresión artísti- } \\
\text { ca en calle. }\end{array}$ & $\begin{array}{l}\text { Reflexiva: cambio } \\
\text { social-institucional. }\end{array}$ \\
\hline $\begin{array}{l}\text { Colectivo infor- } \\
\text { mación alterna- } \\
\text { tiva: Colectivo } \\
\text { Brigada Informa- } \\
\text { tiva Altavoz. }\end{array}$ & $\begin{array}{l}\text { La gota que derra- } \\
\text { mó el vaso. Ya no } \\
\text { tenemos miedo. }\end{array}$ & $\begin{array}{l}\text { Profesional. } \\
\text { Info-activismo. }\end{array}$ & $\begin{array}{l}\text { Revolución/ } \\
\text { derrocamiento. }\end{array}$ \\
\hline
\end{tabular}




\begin{tabular}{|c|c|c|c|}
\hline Productor & Título & $\begin{array}{c}\text { Tipo } \\
\text { de producción }\end{array}$ & Propuesta \\
\hline $\begin{array}{l}\text { Agencia libre de } \\
\text { comunicación } \\
\text { digital: Mientras } \\
\text { tanto en México. }\end{array}$ & $\begin{array}{l}\text { Mexican narco- } \\
\text { government \#Jus- } \\
\text { ticeForAyotzinapa. }\end{array}$ & $\begin{array}{l}\text { Profesional } \\
\text { Infoactivismo. }\end{array}$ & $\begin{array}{l}\text { Reflexiva: cambio } \\
\text { social-institucional. }\end{array}$ \\
\hline $\begin{array}{l}\text { OnG: Ojo Ambu- } \\
\text { lante. }\end{array}$ & $\begin{array}{l}\text { Somos Ayotzinapa } \\
\text { (subtítulos inglés/ } \\
\text { portugués). }\end{array}$ & $\begin{array}{l}\text { Casera, puesta } \\
\text { en escena. }\end{array}$ & $\begin{array}{l}\text { Revolución/ } \\
\text { derrocamiento. }\end{array}$ \\
\hline $\begin{array}{l}\text { Músico: } \\
\text { Carrisoza, J. }\end{array}$ & $\begin{array}{l}\text { Ayotzinapa } 43 \\
\text { Corrido. }\end{array}$ & Casera, musical. & $\begin{array}{l}\text { Revolución/ } \\
\text { derrocamiento. }\end{array}$ \\
\hline $\begin{array}{l}\text { Estudiantes: } \\
\text { Todos Somos } \\
\text { Ayotzinapa. }\end{array}$ & Ayotzinapa vive. & $\begin{array}{l}\text { Semiprofesional } \\
\text { puesta en escena. }\end{array}$ & $\begin{array}{l}\text { Reflexiva: cambio } \\
\text { social-institucional. }\end{array}$ \\
\hline $\begin{array}{l}\text { Blog activismo: } \\
\text { LoQueSigue TV. }\end{array}$ & $\begin{array}{l}\text { \#RegrésalosEPN } \\
\text { \#EPNBringThem- } \\
\text { Back Los queremos } \\
\text { vivos a los } 43 .\end{array}$ & $\begin{array}{l}\text { Producción pro- } \\
\text { fesional, } \\
\text { activismo en red. }\end{array}$ & $\begin{array}{l}\text { Reflexiva: cambio } \\
\text { social-institucional. }\end{array}$ \\
\hline
\end{tabular}

Procedimos al análisis del «storytelling» a partir de las siguientes categorías:

- Identidad. Conjunto de códigos que responden a las preguntas «quién soy», «qué siento», «quiénes son ellos» y «cuál es mi llamado a la acción» (Tilly, 2002).

- Representación. Por la cual entendemos, como Hall (2007), 'el conjunto de significados dados al caso estudiado que observamos en su forma digital en las palabras, frases y emociones aludidas'. También como 'la forma digital que se observa en el tiempo, el audio y las imágenes empleadas'.

- Reflexividad. Basados en Beck (2007), consideramos como tal el conjunto de valores expresados y confrontados, así como la noción de comunidad y reconocimiento del otro a nivel estructural (Honneth, 2007).

Transcribimos el «storytelling» de nuestros sujetos de estudio (13 en total) y bajo nuestras categorías observamos el arco dramático (Le Blanc, 2006) que 
comprende una introducción en donde usualmente se construye la identidad de los actores en disputa, el problema, los objetivos, que corresponde a la representación que nuestros sujetos hicieron de los hechos, el clímax, en donde se ubica al supuesto culpable(s) y la propuesta. ${ }^{6}$ Para contrastar los códigos en disputa, elegimos los discursos más relevantes del presidente Peña Nieto en el periodo seleccionado en el Canal del Gobierno de la República en YouTube: los del 6 y el 29 de octubre de 2014, y el 18 y el 27 de noviembre del mismo año. Estos discursos tuvieron resonancia en los medios tradicionales en el lapso estudiado y que analizamos bajo el umbral de las mismas categorías, sin perder de vista el contexto político y la cobertura de los medios convencionales para proceder a explicar las dinámicas de las relaciones de poder.

\section{HALLAZGOS}

\section{1. «Storytelling» de la sociedad civil}

Los productores audiovisuales de la sociedad civil representaron los trágicos hechos a partir de la empatía, al asumirse como la sociedad y hablar en nombre de los estudiantes desaparecidos y sus familias, lo cual, bajo el clamor de la indignación, articuló el eje de la identificación social. «Todos somos Ayotzinapa» fue el anclaje de significado del hecho histórico desde un lugar compartido de juventud e indefensión contra un enemigo común: el Estado. Diversas representaciones del caso constituyeron el arco dramático de la narrativa mediante la cual se exigió justicia y se denunció la impunidad y la corrupción. Se trató de un relato unificador de ciudadanos organizados que, desde diversos orígenes, con códigos y valores compartidos, dieron un significado común a este suceso de violación a los derechos humanos. La representación del caso tiene una separación al final del arco, donde se bifurca en dos visiones diferenciadas que apuestan, una por el cambio social a través de la revolución y otra por proyectos reflexivos e institucionales (figura 2). La figura del arco dramático, construida por la narrativa de la sociedad civil, se mantuvo firme los tres meses analizados, y fue un fenómeno compartido tanto en YouTube como en otras manifestaciones dentro y fuera del espacio digital.

6. Para el análisis y la integración de los arcos dramáticos de las historias nos apoyamos de manera complementaria y en búsqueda de mayores certezas en el scrapping textual a través de la herramienta Voyant, si bien no fue definitoria para el análisis. 


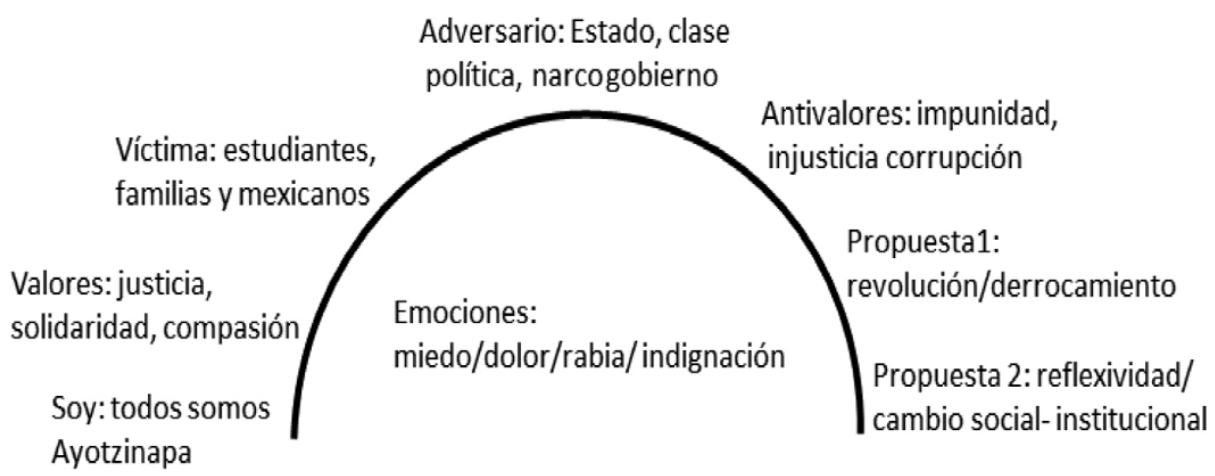

Figura 2. «Storytelling» de la sociedad civil

El arco dramático presenta una manera de agencia ciudadana afectiva y performativa, desde el espacio virtual, a partir de la narrativa en primera persona del plural y la puesta en escena, la poesía y la música como elementos estéti$\cos$ y forma cultural. Las plataformas digitales posibilitan formas de protesta y resistencia, cargadas de emotividad, es decir, no son tratadas por un marco que permita la ponderación y el equilibrio del periodismo profesional y que contrastan con la narrativa oficial. Se detectaron narrativas breves, subjetivas y simples en donde se palpa la existencia del bien y el mal. Evidencian la mediatización de la cultura de la protesta virtual en la forma audiovisual, y en el manejo del tiempo con frases cortas y eficientes cercanas a los formatos televisivos, la mercadotecnia y al poema corto.

La identificación de la sociedad con las víctimas se buscó haciendo referencia a los ámbitos comunes que el ciudadano comparte con los normalistas desaparecidos: la madre, los familiares, la juventud y la condición estudiantil como aspiración a una vida mejor en un país con altos niveles de desigualdad social. Las imágenes de los videos refuerzan esta afinidad dentro del arco dramático. Fotografías de mujeres sufrientes, adolescentes que van a la escuela y ciudadanos que acompañan y se solidarizan mediante marchas. En la narrativa, la referencia a la primera persona del plural (nosotros, somos, unidos) o bien la primera persona del singular a nombre de los desaparecidos, («yo soy uno de $\operatorname{los} 43 »)$, son formas narrativas recurrentes y comunes a todas las producciones.

Detectamos la construcción del adversario común: el Estado (el ejecutivo, el ejército, los partidos políticos y el «narcoestado») como el antagónico ligado a palabras como muerte, miedo, crimen, represión y una patente demanda de 
justicia. Se observó la intención de hacer escuchar la denuncia por la sociedad global, por lo cual algunas producciones están narradas en otros idiomas, principalmente en inglés. El adversario común se construye a nivel visual con símbolos que aluden a la resistencia de un poder represor, fotografías de políticos y policías, mantas y pintas con consignas que denuncian la corrupción, la impunidad y el vínculo de la clase política con el crimen organizado.

Se pueden apreciar las dos propuestas encontradas. Por un lado, el proyecto reflexivo, donde se ubican tanto los que crean conciencia del papel de la ciudadanía respecto al reconocimiento del otro como sujeto de derechos, planteando soluciones ambiguas, hasta los que diseñan acciones de resistencia que pretenden abrir espacios de negociación política. Mientras que en el otro extremo se encuentra el proyecto revolucionario, los que consideran que las vías institucionales para la negociación política se han agotado.

La confrontación con el adversario se da a partir de valores que son representados como si fuesen exclusivos de la sociedad civil, tales como justicia, solidaridad y compasión. A partir de estos valores se construye un proyecto de reflexividad que demanda el reconocimiento social de los normalistas y sus familias. Reconocemos que las producciones podrían funcionar como activadores del tejido social y de comportamientos solidarios activos cuando sus propuestas son por vías no violentas (Nos, 2012: 215).

Aunque no contamos con evidencias que sugieran que las narrativas estudiadas influyeron en la agenda de los medios tradicionales, lo cual no es objetivo del presente artículo, encontramos que el caso Aytozinapa generó 1088 menciones en 28 periódicos mexicanos entre el 27 de noviembre y 31 de diciembre de 2014. Contra las intenciones del gobierno de relegarlo, Ayotzinapa has sido, sin duda alguna, el caso de violación a los derechos fundamentales que ha marcado a la presidencia de Peña Nieto. ${ }^{7}$

\section{2. «Storytelling» del presidente}

El presidente representó la tragedia de forma diferente en cada uno de los discursos analizados, como puede apreciarse en las siguientes figuras. El arco dramático fue moviéndose de acuerdo al descontento social, pero el primer y tercer discurso fueron los más desfasados con respecto al clamor ciudadano,

7. Para este conteo que sirve para contextualizar el clima de opinión usamos el sistema de monitoreo eMedios, que toma en cuenta los periódicos que mencionaron la palabra Ayotzinapa entre el 27 de septiembre y el 31 de diciembre de 2014. 
mientras que el segundo y el cuarto mostraron más evidencia de un esfuerzo presidencial por armonizar y alcanzar el liderazgo en la narrativa que desde un inicio fue tomada por la ciudadanía. Mediante una comunicación política controlada -a excepción del tercero- el presidente se comunicó a la nación en un formato tradicional de rueda de prensa, donde leyó un texto que fue grabado en tomas cerradas en las que pueden apreciarse tres símbolos del poder: el presidente, la bandera mexicana y el escudo nacional. En el tercer discurso, en el marco de un evento llevado a cabo en el Estado de México (lugar de donde es oriundo), el presidente habló con confianza del tema Ayotzinapa: sin guión y con toma abierta en un espacio poco controlado tuvo lugar el «storytelling» más desfasado respecto a la sociedad civil en el periodo analizado. La postura reactiva de las narrativas del presidente respecto a la sociedad civil obliga a la presentación de cuatro diferentes arcos dramáticos correspondientes a cada discurso analizado.

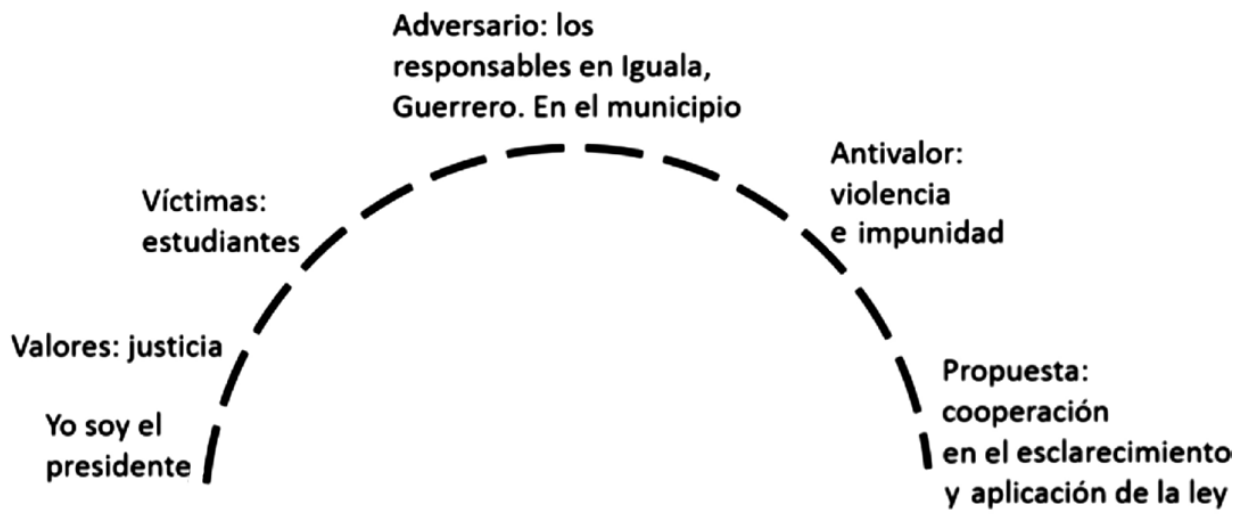

Figura 3. Primer discurso presidencial, 6 de octubre 2014

Gobierno de la república «Mensaje a medios del presidente Peña Nieto sobre Iguala» 


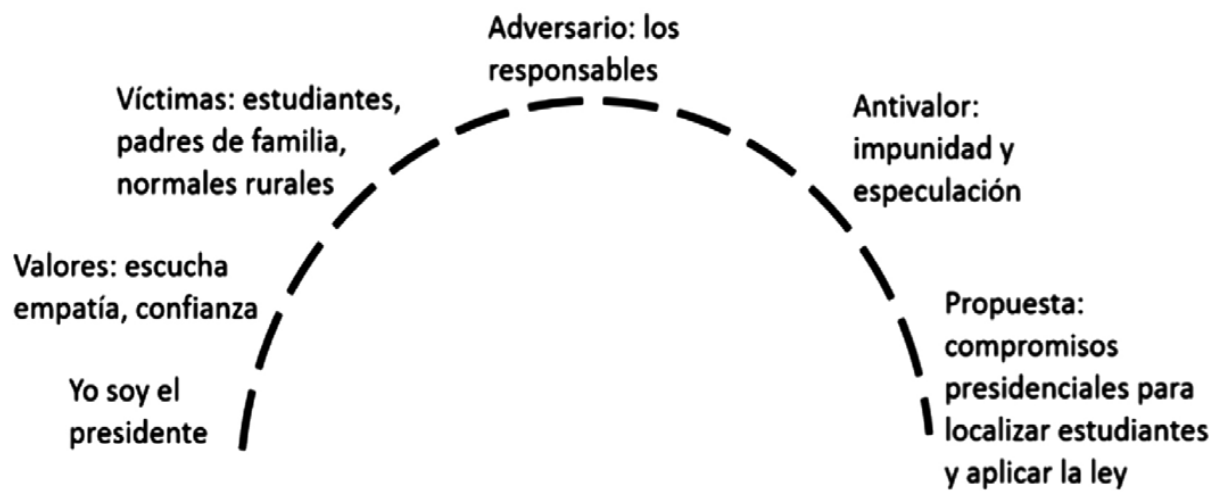

Figura 4. Segundo discurso presidencial, 29 de octubre 2014 Gobierno de la República: «Ayotzinapa Mensaje a medios del Presidente Peña Nieto»

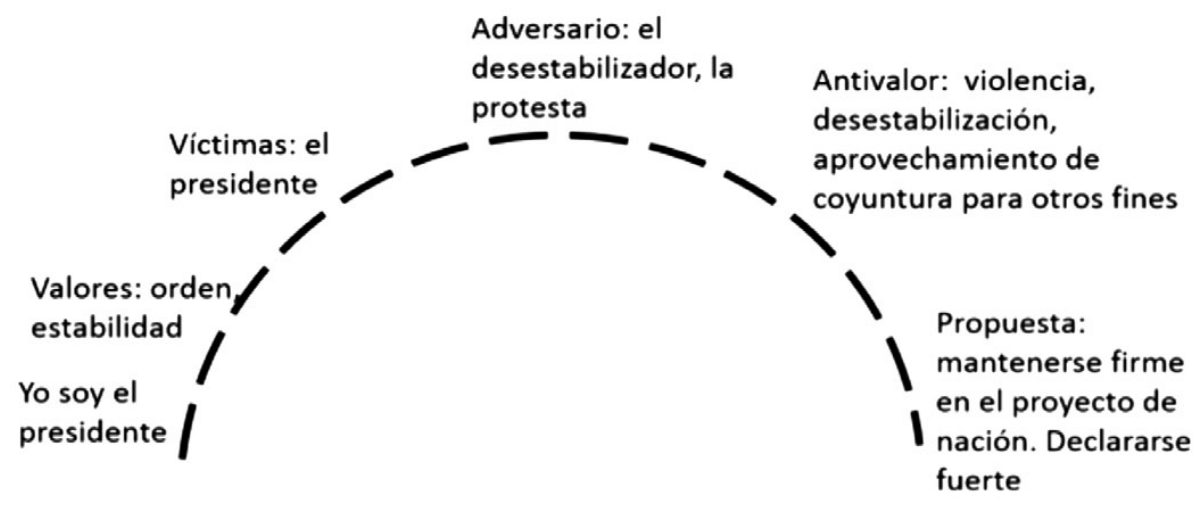

Figura 5. Tercer discurso presidencial, 18 de noviembre de 2014 Gobierno de la Repúbica «Inauguración de la Ciudad de la Salud para la Mujer» 


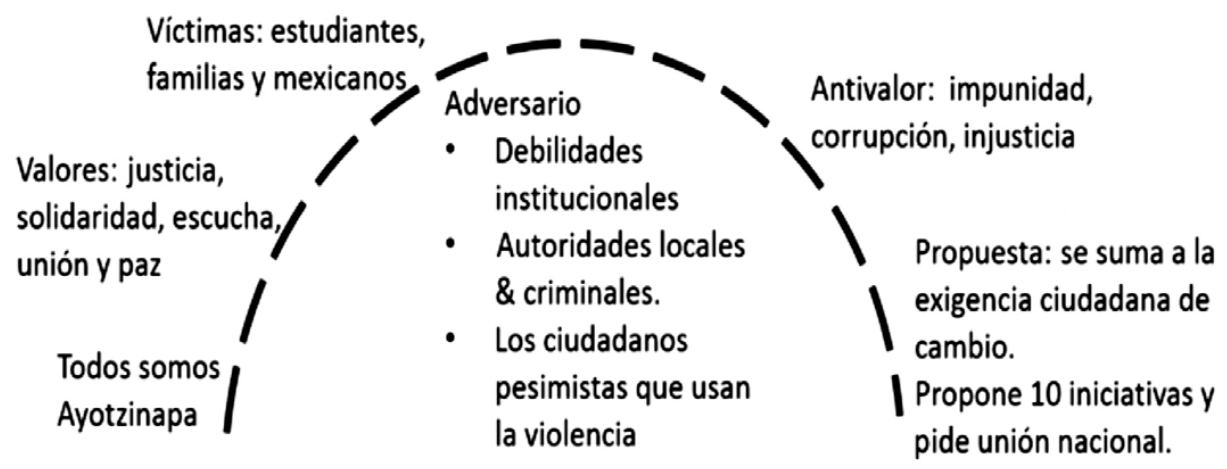

Figura 6. Cuarto discurso de Peña Nieto, 27 de noviembre de 2014 Gobierno de la República: «Mensaje a la Nación: por un México en Paz con justicia, unidad y desarrollo»

La historia oficial partió de la identidad del poder hegemónico confrontada en cada momento por los activos padres de los estudiantes. La representación del otro no fue expresada con claridad, sino que en cada uno de los discursos analizados el presidente construyó una identidad ambigua del enemigo. Así, los adversarios para el Estado fueron cambiando en cada uno de los cuatro discursos analizados. En el primero, el antagónico fue la autoridad local de Ayotzinapa; ${ }^{8}$ en el segundo evadió señalar responsables; en el tercero reclamó a los ciudadanos pesimistas que se oponían a su proyecto presidencial en una clara criminalización de la protesta. Finalmente no fue hasta el cuarto discurso que el presidente reconoció las debilidades institucionales del país y la existencia del crimen organizado, con lo cual se encontró discursivamente con el clamor social .

En los dos primeros discursos (figuras 3 y 4 ) se observa un presidente que dice que hará cumplir la ley y llama a tener confianza institucional, cuando en los hechos era confrontado en las redes, las marchas en la calle, los medios y los organismos internacionales, como la Organización de las Naciones Unidas y la Comisión Interamericana de Derechos Humanos. ${ }^{9}$ Ante lo que sucedía en las

8. Las primeras detenciones de presuntos culpables fueron las del alcalde de Ayotzinapa y su esposa.

9. En el periodo estudiado tuvieron lugar tres marchas multitudinarias en la Ciudad de México los días 2 y 22 de octubre y 9 de noviembre de 2014. 
redes y las calles, el presidente viajó a China para asistir a un foro multilateral, lo cual avivó la indignación (CNN México, 2014). El tercer discurso se dio en un marco de indignación por el viaje y ante el rechazo social por las acusaciones de conflicto de interés en la compra de su lujosa casa. La narrativa del 18 de noviembre de un presidente molesto con el enemigo (todo aquel que le critica) se desplazó hacia quienes desean desestabilizar a su gobierno pasando por una enérgica condena de la protesta (figura 5).

Fue el 27 de noviembre, con un malestar acumulado que traspasaba fronteras por el entramado mediático digital y tradicional, cuando el presidente se mostró solidario al decretar diez medidas para fortalecer la seguridad en los municipios del país. Hasta entonces, dos meses después, se pudo observar una tardía empatía cuando el presidente se apropió de la representación social: \#TodosomosAyotzinapa (figura 6).

A partir del análisis de la narrativa y el contexto, pudimos palpar la lucha hegemónica y contrahegemónica, en la cual hay dos representaciones contrapuestas y en disputa. Observamos una narrativa social de resistencia, emocional, clara en sus señalamientos y demandas, ante un discurso presidencial inconexo y desarticulado que condenó la protesta y mezcló el enojo personal por las acusaciones en su contra por conflicto de interés en la comprade su casa.

\section{DISCUSIÓN Y CONCLUSIONES}

Las herramientas y fórmulas para filtrar textos audiovisuales son útiles porque permiten llegar a una muestra de manera objetiva centrada en los atributos buscados dentro de un mar de producciones en menos tiempo. Probablemente, mientras se perfeccionen, sea conveniente mezclar su uso con técnicas de búsqueda manual. Ambas técnicas tienen el inconveniente de estar circunscritas a las posibilidades que brinda YouTube. Coincidimos con las hipótesis relativas a la capacidad estratégica que las narrativas ofrecen para el cambio social reflexivo que, en algunos casos como el aquí analizado, puede presionar a los tomadores de decisiones a ejercer algún tipo de acción. Analizar el storytelling a través de los arcos dramáticos resulta útil para la toma de decisiones políticas y para la transformación positiva de los conflictos sin perder de vista el contexto sociopolítico en que se desarrolla.

Es así que el discurso contrahegemónico, anidado en las plataformas digitales y amplificado por el sistema de medios global que confrontó al gobierno mexicano configuró una esfera pública global con un sentido de rechazo, indignación y confrontación con el poder alrededor de este episodio ante un gobierno que intentó aislar el caso a una comunidad de un estado en donde el $24.5 \%$ de 
la población vive en pobreza extrema y el $65.2 \%$ en situación de pobreza (Coneval, 2014). Las producciones afectivas de los ciudadanos constituyeron un elemento clave para la movilización offline y moldearon el estado de ánimo social, lo cual se constata con el índice de popularidad a la baja del presidente en los tres meses subsecuentes a que se conociera el caso, así como con en el índice abrumador de conocimiento de las marchas y protestas y, por supuesto, en la reacción del gobierno de México que, pese a intentarlo, no pudo eludir la responsabilidad política de la federación para atender un caso de desapariciones forzadas.

A un año de conocerse los hechos, el caso de Ayotzinapa consiguió alcance global, entre otras causas, gracias a un entramado mediático digital supranacional que ayudó a difundir y concienciar sobre la situación de los derechos humanos en México más allá de sus fronteras. La presión internacional sobre el gobierno mexicano para esclarecer los hechos continuó e incrementó en meses posteriores. Así, aceptó una investigación independiente por parte de la Comisión Interamericana de Derechos Humanos, que concluyó, meses más tarde, que la historia de Ayotzinapa construida por el gobierno federal que involucró a los policías locales y al crimen organizado - quienes habrían ordenado la incineración de los estudiantes- carece de sustento empírico (CIDH, 2015). El grupo de expertos sugirió una línea de investigación en la cual habrían estado enterados de los hechos los tres órdenes de gobierno: el federal, el estatal y el municipal respectivamente. Las conclusiones fueron aceptadas por el gobierno que se comprometió a tomar en cuenta sus sugerencias para realizar un nuevo peritaje. No solo a nivel regional, sino que hasta el Alto Comisionado para los Derechos Humanos de las Naciones Unidas (2015) ha urgido a resolver con transparencia y agilidad la preocupante situación de los derechos humanos en México develada a partir de la tenaz denuncia de la sociedad civil analizada en este artículo. Constatamos a través del presente estudio una disputa por la construcción de la historia de Ayotzinapa, donde la narrativa inestable por parte del Gobierno Federal pudiera anticipar la extensión de la incertidumbre y tensión política en el futuro próximo. La pregunta continúa siendo si estas representaciones y acciones de indignación y protesta, además de informar y posibilitar una toma de conciencia ciudadana, alcanzan a influir en la toma de decisiones significativa. Con base a lo observado, ratificamos que las narrativas por sí solas no alcanzan a modificar per se el devenir social, si bien organizan a la sociedad civil y presionan al poder hegemónico a escuchar y a dar señales de entendimiento. 


\section{REFERENCIAS BIBLIOGRÁFICAS}

Animal Político (2014): «Peña Nieto enfrenta una «caída histórica» de su aprobación», Animal Politico, recuperado de http://goo.gl/aqYPN9.

Asamblea General de NaCiones Unidas (1993): «Declaración sobre la protección de todas las personas contra las desapariciones forzadas», recuperado de http://goo.gl/r8hvjr.

BECK, U. (2007): «Teoría de la modernización reflexiva» en BERIAIN, J. (comp.) (2007): Las consecuencias perversas de la modernidad, Barcelona, Antrophos. 201-222.

Bengtsoon, A.; Christensen, H. (2012): «The political competence of Internet participants», en B. D. LoAder; D. Mercea (eds.) (2012): Social Media and Democracy. Innovations in Participatory Politics, Nueva York, Routledge, 132-149.

Bennet, W.; Segerberg, A. (2012): «Digital media and the personalization of collective action. Social technology and the organization of protests against the global economic crisis», en LoAder, D.; Mercea, D. (eds.) (2012): Social Media and Democracy. Innovations in Participatory Politics, Nueva York, Routledge. 13-53.

Colectivo Brigada Informativa Altavoz (2014-11-07): «La gota que derramó el vaso. Ya no tenemos miedo», recuperado de https://goo.gl/ffNBon.

Burgess, J. (2006): «Hearing Ordinary Voices: Cultural Studies, Vernacular Creativity and Digital Storytelling», Continuum, Journal of Media \& Cultural Studies 20 (2), 201-214.

Burgess, J; Greeen, J. (2009): YouTube, Malden, Polity Press.

Carrisoza, J. (2014-11-11): «Ayotzinapa 43 Corrido», recuperado de https:// goo.gl/xndYUD.

Castells, M. (2004): La era de la información. Economía, sociedad y cultura. El poder de la identidad, México, Siglo XXI.

Castells, M. (2012): Networks of outrage and hope. Social movements in the Internet Age, Malden, PolityBooks.

Castillo, M.; Meneses, R. (2015): «Dinámicas de comunicación y resistencia. El caso de \#Ayotzinapa en YouTube». en Nos, E.; ArÉvalo, A.; FARNÉ, A. (eds.) (2015): Comunicambio: comunicación y sociedad civil para el cambio social, Madrid, Fragua.

CIDH. (2015): «Ayotzinapa, investigación y primeras conclusiones», recuperado de http://goo.gl/xywUgq. 
CNN MÉxico (2014): «Peña llega a China en medio de la polémica por Ayotzinapa y la mansión», CNN México, http://goo.gl/0OZYTG.

Coneval (2014): «Estadísticas de pobreza en Guerrero», recuperado de http:// goo.gl/zCvo1B.

Couldry, N. (2008): «Mediatization or mediation? Alternative understandings of the emergent space of digital storytelling», New Media and Society, 10 (3): 373-91.

Couldry, N. (2012): Media, Society, World. Social Theory and Digital Media Practice, Cambridge, Polity Press.

Crowley, M. (2014): «Saving Mexico», Time, recuperado de http://goo.gl/ HUHIEP.

Gobierno de la República (2014): «Mensaje a medios del Presidente Peña Nieto sobre Iguala, Guerrero», recuperado de https:/goo.gl/lRthzV.

- (2014 b): «Ayotzinapa: Mensaje a medios del presidente Peña Nieto», recuperado de https://goo.gl/q4YG5R.

- (2014c): «Inauguración de la Ciudad de la Salud para la Mujer», recuperado de https://goo.gl/5zhp9o.

- $(2014 d)$ : «Mensaje a la Nación: por un México en paz con justicia, unidad y desarrollo», https://goo.gl/W4t1wB.

Goffman, I. (1974): Frame Analysis, Nueva York, Harper \& Row.

Hall, S.; Jefferson, T. (2014) «Retorno a rituales de resistencia » en Hall, S.; T. JEFFERSON (eds.) (2014): Rituales de resistencia. Subculturas juveniles en la Gran Bretaña de posguerra, Madrid, Traficantes de Sueños. 15-54.

Hall, S. (2007): «The work of Representation» en Hall, S; Evans, N.; S. Nixon (coord.) (2007) Representation, Londres, SAGE y Open University, 1-46.

Honneth, A. (2007): Reificación. Un estudio en la teoría del reconocimiento, Buenos Aires, Katz.

INEGI. (2013): «Encuesta sobre disponibilidad y uso de las tecnologías de la información MODUTIH 2013», recuperado de http:/goo.gl/wTtrCM.

- (2014): «Datos preliminares revelan que en 2014 se registraron 19.669 homicidios», recuperado de http://goo.gl/HHwxf0.

Instituto Nacional Electoral [INE] (2014): «Informe País sobre calidad de la ciudadanía en México», recuperado de http://goo.gl/7c0E9u.

JACKSON, M. (2002): The politics of storytelling. Violence, transgression and intersubjectivity, Copenhague, Museum Tusculanum Press.

JENkins, H. (2013): Spreadable Media, Nueva York, NYU Press.

LAMBERT, J. (2006): Digital storytelling: Capturing lives, creating community, Berkeley, Digital Diner Press. 
LE BLAnC (2006): «Tools for creating Dramatic Game Dynamics» en SALEN, K, Y Zimmerman, E. (2006): The Gamer Designer. A Rules of Play Anthology, Cambridge, MIT Press. 438-459.

López, A. V. (2014). «Versos de Ayotzinapa-Carmina Cannavino», recuperado de https://goo.gl/sXyOYs.

LoQueSigue tv (2014): «\#RegrésalosEPN \#EPNBringThemBack, Los queremos vivos a los 43», recuperado de https://goo.gl/mzXsmF.

MeluCCI, A. (1996): Challenging Codes. Collective Action in the Information Age, Cambridge, University of Cambridge Press.

MeneSeS, M. E. (2014): «Ayotzinapa en Twitter», La silla rota, recuperado de http://goo.gl/a3tt4w.

- (2015): ciberutopías, democracia, redes sociales y movimientos red, México, Porrúa y Tecnológico de Monterrey.

Mientras tanto EN México (2014): «Mexican narcogovernment \#JusticeForAyotzinapa», recuperado de http://goo.gl/kmmxM8.

NoAM, E. (2011): «International Media Concentration», Social Science Research Network, recuperado de http://goo.gl/Qprfmr.

Nos, E.; Iranzo, A.; FArné, A. (2012): «La eficacia cultural de la comunicación de las ONGD: los discursos de los movimientos sociales actuales como revisión», Cuadernos de Información y Comunicación CIC, 17, 209-237, recuperado de http://dx.doi.org/10.5209/REV_CIYC.2012.v17.39265.

OJoAmbulante (2014): «Somos Ayotzinapa (subtítulos inglés/portugués)», recuperado de https://goo.gl/V306ac.

Papacharissi, Z; Oliveria, M. (2012): «Affective News and Networked Publics. The Rhytms of New Storytelling on \#Egypt», Journal of Communication, 62 (02), 266-282.

Papacharssi, Z. (2015): Affective Publics. Sentiment, Technology and Politics, Madison, Oxford University Press.

Parametría (2014): «Las marchas por Ayotzinapa», Parametría, recuperado de http://goo.gl/wEi1PB.

PAROK, ShD (2014): «Solo quería ser maestro Ayotzinapa. Canción + link de descarga», recuperado de https://www.youtube.com/watch?v=pE8wBQa BRO

Poletti, A. (2011): "Coaxing an intimate public: Life narrative in digital storytelling, Continuum», Journal of Media \& Cultural Studies, 25 (01), 73-83.

RA'Ad Al Hussein, Z. (2015): «Declaración del Alto Comisionado de la ONU para los Derechos Humanos, Zeid Ra'ad Al Hussein, con motivo de su visita a México, ONU-DH», recuperado de http://goo.gl/JnEUKZ 
Redacción AN (2014): «La casa blanca de Enrique Peña Nieto (investigación especial)», Aristegui Noticias, http://goo.gl/Qss4GB.

Reynoso, G. (2014-10-17): «Performance Ayotzinapa. Estudiantes y maestros de la ENAT 16/10/14 (GRL 9182»), recuperado de https://goo.gl/2tng5L.

Sampedro, J. y Resina (2010): «Opinión Pública y Democracia deliberativa en la Sociedad red», Revista Ayer, 80 (4), 139-162. recuperado de http:// goo.gl/KRYC3p.

Tilly, C. (2002): Stories, Identities, Political Change, Ofxord, Rowman and Littlefield.

Todos somos Ayotzinapa. (2014): «Ayotzinapa vive», recuperado de https:// goo.gl/TF83d6.

TREJo, R. (2011): «Televisión: de mala calidad y en pocas manos», AMEDI, Panorama de la Comunicación en México 2011, Desafios para la calidad y la diversidad, México /AMEDI /LXI Legislatura.

TuFte, T. (2015): Comunicación para el cambio social. La participación y el empoderamiento como base para el desarrollo mundial, Barcelona, Icaria Antracyt.

Van DiJck, J. (2013): The Culture of Connectivity: a Critical History of Social Media, Nueva York, Oxford University Press.

Williams, R. (2011): Televisión. Tecnología y Forma Cultural, Buenos Aires, Paidós.

World ECONOMic Forum [WeF]. (2014): «The Global Competitiveness Report 2014-2015», recuperado de http://goo.gl/q6OjwH. 